\title{
How Segmented Are Skilled and Unskilled Labour Markets: The Case of Beveridge Curves*
}

\author{
Lei Lei Song and Elizabeth Webster \\ Melbourne Institute of Applied Economic and Social Research \\ The University of Melbourne
}

Melbourne Institute Working Paper No. 14/01

ISSN 1328-4991

ISBN 0734015186

November 2001

\begin{abstract}
*This paper was funded by a grant from the ARC. Thanks are due to Duy Tien Tran for assisting with the data collection, and Nilss Olekalns, Guyonne Kalb, Paul Frijters, Daniel Hamermesh, Richard Jackman and John Creedy and participants at the Melbourne Institute of Applied Economic and Social Research Conference on Unemployment August 2001 for useful comments. Views expressed represent those of the authors. All errors remain the responsibility of the authors.
\end{abstract}

Melbourne Institute of Applied Economic and Social Research The University of Melbourne

Victoria 3010 Australia

Telephone (03) 83443701

Fax (03) 83445630

Email melb.inst@iaesr.unimelb.edu.au

WWW Address http://www.melbourneinstitute.com 


\begin{abstract}
This paper tests whether there is empirical evidence that two distinct Beveridge curves for the skilled and unskilled aggregate markets. The results support the dualism hypothesis and specifically find that the skilled labour segment is more efficient at matching workers with jobs and/or has lower turnover rates. Lower turnover rates may be indicative of a better prior match. It also found that other shift variables, such as the replacement rate, the incidence of long-term unemployment, the immigration rate and the market circumstances in the other segment, had differential effects on each curve.
\end{abstract}




\section{Introduction}

There has been discussion in the literature about whether the aggregate labour market functions, to all intents and purposes, as separate skilled and unskilled markets. ${ }^{1}$ This paper tests whether this dualism is reflected in a common summary operational measure of labour markets: the Beveridge Curve.

The position of a Beveridge Curve indicates how promptly job openings are filled by unemployed job seekers and the rate of vacancy creation due to worker job turnover. A market segment, which fills its vacancies quickly, will generally exhibit flatter curves and curves which are closer to the origin. Similarly, a market with lower job turnover has a Beveridge curve that is closer to the origin. The greater is the tendency for employers to believe that the unemployed would not make suitable employees or for the unemployed to reject available jobs, then the higher are both vacancies and unemployment, even though the state of labour market balance, as represented by the ratio of vacancies to unemployment, is the same. The greater the tendency for this pattern of behaviour to develop as economic activity rises, the steeper the Beveridge Curve. Both scenarios indicate some level of labour market malfunction. The higher is the mismatch rate between employers and job seekers in any market segment, the more likely that jobs will be filled by people from other markets or people not in the labour force or that job will not filled at all.

This paper makes empirical estimates of Beveridge curves for separate skilled and unskilled labour markets. ${ }^{2}$ The former refers to people whose current or last jobs were in managers and administrators, professional, associate professional or trade occupations. The 
latter covers the major occupational groups of clerks, salespeople, plant and machine operators, service workers and labourers. ${ }^{3}$ Following the literature in this area, ${ }^{4}$ the main independent variables used in the estimation includes, for either group, the replacement rate, the incidence of long-term unemployment and the immigration rate.

Section 2 of this paper discusses the model used to estimate the Beveridge curves. Section 3 describes the unemployment vacancy co-ordinates, section 4 presents results from the econometric estimation procedures and section 5 finishes with a short conclusion.

\section{The Beveridge curve relationship}

The Beveridge curve summaries the relationships between unemployment and vacancies, determined by flows into and out of unemployment and jobs, together with the job-matching process. The aggregate full employment point for the labour market is characterised by an equality of unemployed people and vacant jobs. If job matching is a production process, then the Beveridge curve can be thought of as the isoquant of two inputs of this production process. $^{5}$

In an extremely simple model in which jobs and labour are homogeneous and the matching service is instant and costless, the Beveridge curve keeps to the two axes and vacancies do not exist simultaneously with unemployed persons and vice versa. If the matching service takes a given defined period because of the cost-time trade-off associated with search, advertising, screening and recruitment, the Beveridge curve shifts out from the

\footnotetext{
${ }^{1}$ See, for example, Nickell and Bell (1995).

${ }^{2}$ For a discussion of unemployment and skills in Australia, see Vickery (1999).

${ }^{3}$ The former refer to the Australian Standard Classification of Occupations (ASCO) - Second Edition, categories 1,2,3 and 4. The latter include categories 5,6,7,8, and 9 .

${ }^{4}$ See Budd et al. (1988), Jackman et al. (1990), Layard et al. (1991), and Webster (1999).
} 
origin. If, in addition, jobs and labour are heterogeneous, the curve changes shape to form a curve or single line as shown in Figure 1.

Common matching factors which may alter the shape and position of the curve include the pecuniary costs of matching, job seekers' incentives to find a match (the pecuniary gain from taking a job and leaving unemployment), separation rates of workers from jobs, the degree of responsiveness of labour supply institutions to market demand, the level of skill specificity and a measure of how job ready the unemployed are.

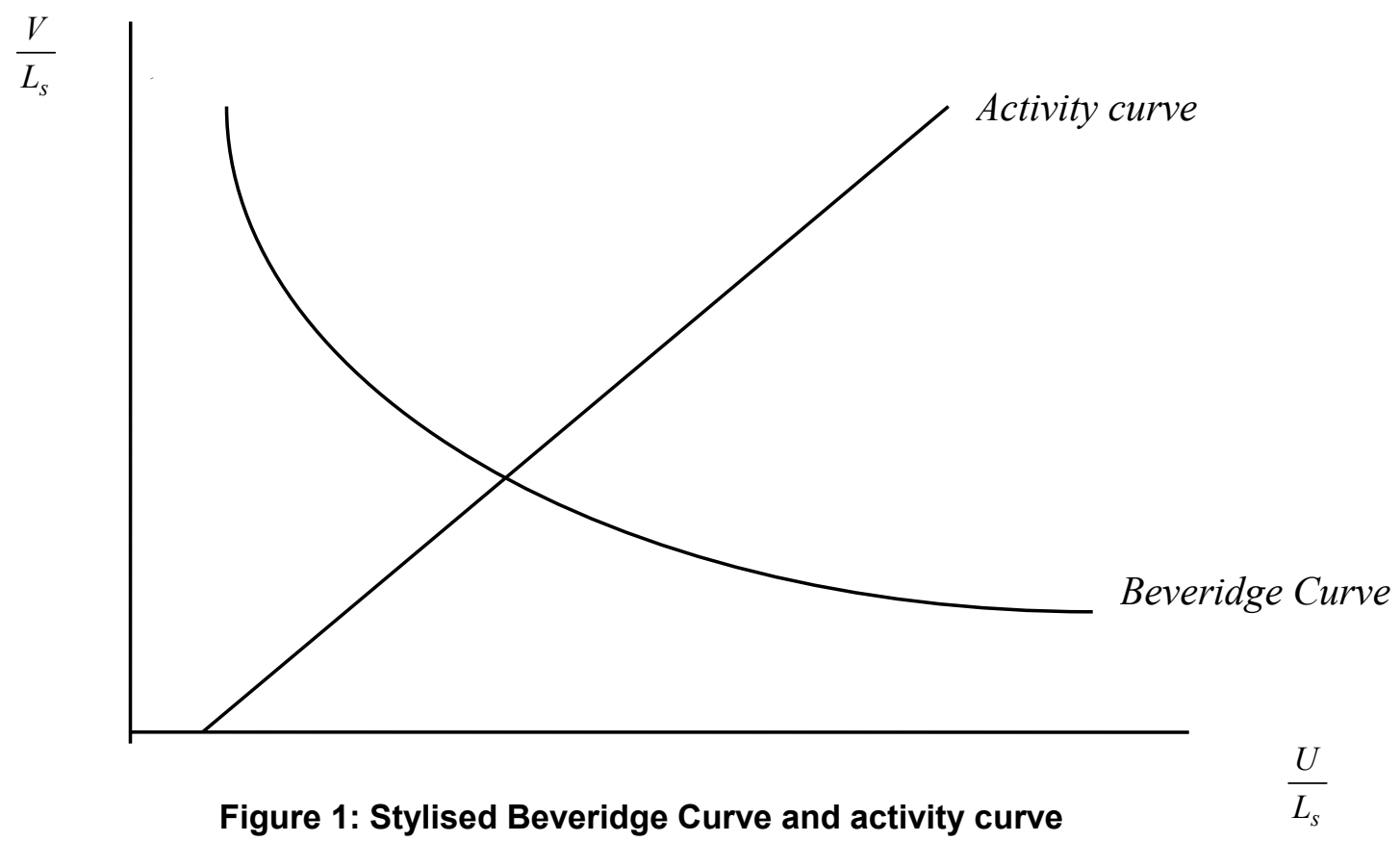

A lower rate of unemployment benefits relative to offered wages (the replacement rate) should increase the incentive for job seekers on unemployment benefits to quickly take a job. Similarly, the incidence of long term unemployment may indicate a greater pecuniary need

\footnotetext{
${ }^{5}$ See Pissarides 1986 and Blanchard and Diamond (1989) for further detail.
} 
for paid work, but alternatively may according to the 'hysteresis' theories, indicate a more de-moralised, less 'work ready' and less search efficient pool of jobseekers. Higher immigration rates may also generate a greater incidence of highly motivated job seekers, but people qualified overseas may also be harder to match because of the non-transferability of country-specific skills, lack of recognition for their foreign qualifications and language barriers.

If the hypothesis assumes more than one market segment, then flows between segments must be considered. Since there is no data of flows between the segments, an appropriate way is to have an indicator of the state of one labour segment in the Beveridge curve equation of the other segment. This paper takes the ratio of unemployment to vacancies as the indicator.

In the literature, it is general to derive the Beveridge curve from the estimated matching function, in which the number of new hires is the function of the stocks of unemployed workers and vacant jobs. ${ }^{6}$ Since there is no data of new hires for skilled and unskilled labour in Australia and also in order to avoid intractable reduced-form equations, the structural relationship for the Beveridge curve is modelled in linear forms in this paper. ${ }^{7}$ Specifically:

$$
v_{i, t}=\beta_{1 i}+\frac{\beta_{2 i}}{u_{i, t}}+\beta_{3 i} R P_{i, t-1}+\beta_{4 i} L T_{i, t-1}+\beta_{5 i} I M_{i, t-3}-\beta_{6 i} \Delta A_{i, t-1}+\beta_{7 i} S_{t}+\beta_{8 i} \frac{u_{j, t}}{v_{j, t}}+\varepsilon_{i t}
$$

Where $u$ is the unemployment rate for each segment

$$
v \text { is the vacancy rate }
$$

\footnotetext{
${ }^{6}$ See, for example, Pissarides (1986), and Blanchard and Diamond (1989), Baker et al. (1996) and Bleakley and Fuhrer (1997).

${ }^{7}$ The equations in both linear and log-linear forms are estimated and yield very similar results, therefore only the estimation results for the equations in linear forms are shown in the paper.
} 
$R P$ the replacement rate

$L T$ the incidence of long-term unemployment (long term unemployment as a ratio of total unemployment)

$I M$ the ratio of immigrants to labour supply

$\Delta A$ recent changes in economic activity

$S$ is a seasonal dummy (the fourth quarter) for normal time of entry for school leavers

$u_{j} / v_{j}$ the state of the other segment

$i, j$ represents a single market segment, $i \neq j$

$t$ is the quarterly time subscript

Implicitly, equation (1) assumes that the underlying job matching process, from which the Beveridge curve is derived, is stable. The stability of the equations has to be tested in the sample period. The efficiency (or productivity) of the job matching process is affected by the replacement rate, long term unemployment and immigration. The equation also assumes that the stocks of unemployment and vacancies in one segment may affect the job matching process in the other segment.

In addition, there are two short-term effects which should temporarily displace the economy from its normal Beveridge curve. From the demand side, upturns in economic activity will cause vacancies to temporarily rise in the period between new jobs being advertised and filled. (Conversely for economic downturns). From the supply-side, sudden seasonal influxes of jobseekers from the educational sector should also be accounted for.

Ideally, all variables should be disaggregated according to market segment, however, this has not been entirely possible for the unemployed and by inference, the long term unemployed and the labour force. Only people who have held a full-time job within the last two years for two weeks or more, have a recorded last occupation. To the extent possible, the seasonal exclusion of new labour force entrants has been controlled for in the model by the seasonal supply side dummies. However, the largest effect is expected to be an understatement of the unemployment rates and the incidence of long term unemployment due 
to the exclusion of the very long term unemployed and this is expected to affect mainly the unskilled sector.

Disaggregating vacancies had been difficult and a series of recent engagements by occupation has been employed to apportion aggregate vacancies by occupation (more details are given below). Because vacancies are endogenous to the system of equations, it is also instrumented (see the data appendix for further explanation). The incidence of long-term unemployment variable has been lagged by one period to eliminate possible endogeneity and possible lagged effects on the Beveridge curves. Because it takes time for a new immigrant to become an active labour market participant, the immigration rate is lagged by three quarters. This lag should also remove the likely effect the unemployment rate has on government immigration policies and emigration. ${ }^{8}$ The replacement rate is lagged by one period due to its lagged effects on the relationship between vacancies and unemployment.

The remaining task is to model the activity curve as the observed position of the economy on the Beveridge curve depends on the level of aggregate economic activity. Two identities describe this 'activity' relationship:

$$
\begin{aligned}
& L_{d i}=E_{i}+V_{i} \\
& L_{s i}=E_{i}+U_{i}
\end{aligned}
$$

Where $L_{d}=$ total demand for labour

$L_{S}=$ total supply of labour

$E=$ total employment

$V=$ total vacancies

$U=$ total unemployed persons

$i, j$ represents a single market segment, $i \neq j$.

\footnotetext{
${ }^{8}$ Withers and Pope (1985) find a positive relationship for this. It is also observable if one views the data.
} 
Substituting the first equation into the second and dividing by $L_{s}$ gives:

$$
v_{i}=\frac{L_{d_{i}}-L_{s_{i}}}{L_{s_{i}}}+u_{i} .
$$

The first term on the right hand side represents the degree to which the economy is operating at or below full capacity. Graphing this activity equation gives us a straight line in Figure 1 above, and together with the Beveridge relationship a determinant rate of vacancies and unemployment.

The activity curve can be modelled as:

$v_{i t}=\alpha_{1 i}+\alpha_{2 i} \Delta C_{t}+\alpha_{3 i} S_{t}+u_{i t}+\varepsilon_{2 t}$

if it assumed that $\frac{L_{d}-L_{s}}{L_{s}}=b_{1}+b_{2} \Delta C+b_{3} S$.

Where $C$ is an indicator of the level of full capacity of the economy

$S$ is a dummy to capture the seasonal effect of school leavers.

Coefficients $b_{1}$ and $b_{2}$ should crudely reflect changes in rates of labour hoarding, hidden or marginal unemployment and the use of imports and offshore production in response to intransigent vacancies.

\section{Comparative vacancy and unemployment rates}

Figure 2 presents the observed vacancy and unemployment rate co-ordinates for the skilled and unskilled labour market segments in Australia. The most striking implied feature is that the skilled Beveridge curve is closer to the origin than the unskilled Beveridge curve. While, this may reflect a real discrepancy between the markets, the difference may be over- or under-exaggerated by the way skilled and unskilled vacancies have been calculated. 
Apportioning vacancies by relative new engagement rates assumes that vacancies in each segment are of equal average duration during any given year; an assumption that does not appear realistic. While Australia does not collect vacancy data by occupation or duration, it is collected annually in the Netherlands. Data from 1992 to 2000, show that unskilled vacancies are filled in 85 per cent the time as skilled vacancies. The estimations below use vacancies that have been estimated on the assumption that this duration differential also applies in Australia. The robustness of this assumption is tested through a sensitivity analysis.

Abstracting for the moment from this difficulty, the observed points in Figure 2 imply that both Beveridge curves are downward sloping and possibly shifted outward in 1993 or 1994 following the recession of 1990-91.

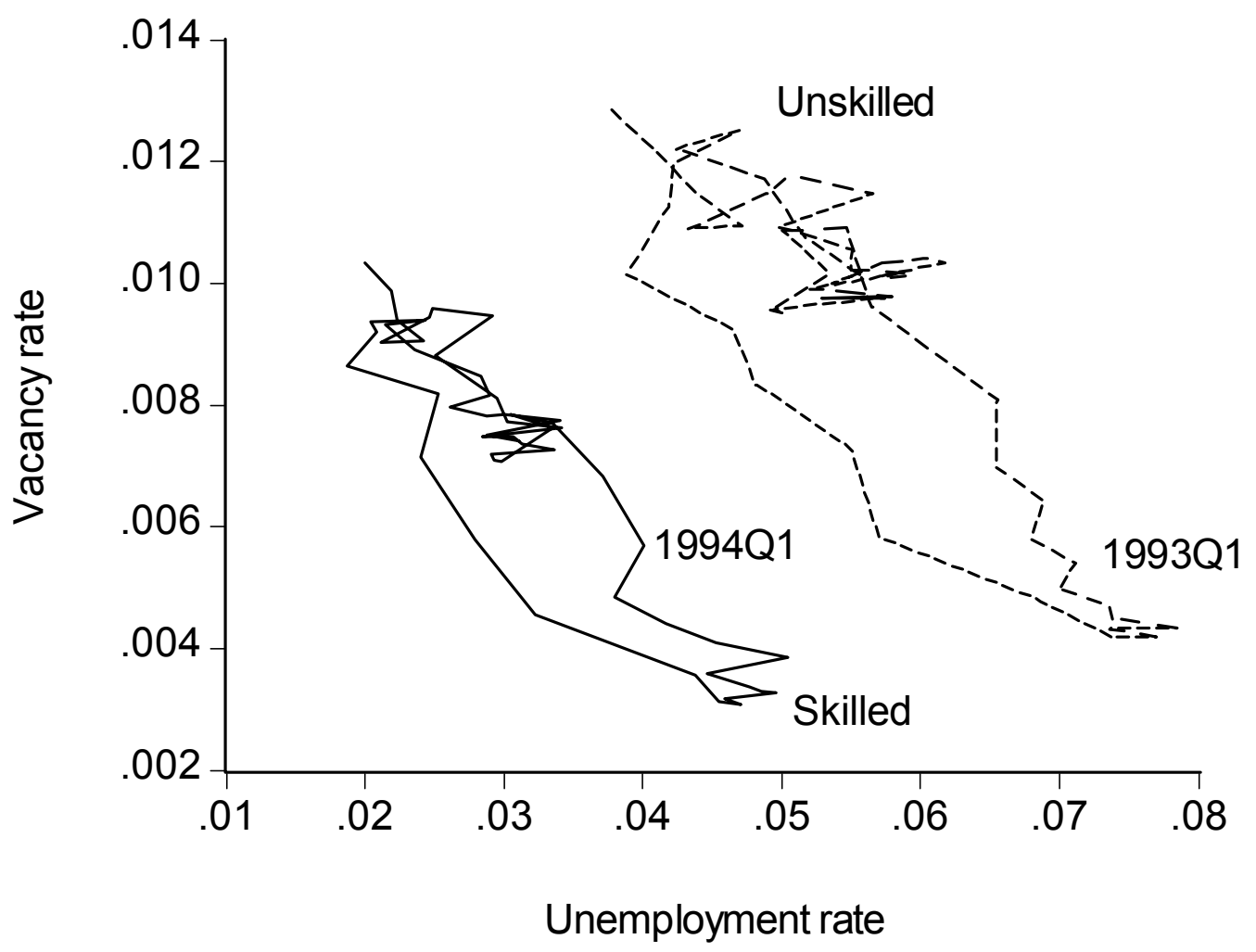

Figure 2: Unemployment and vacancy rates in Australia: skilled and unskilled (1986-1999) 


\section{Estimation results}

Since the unemployment rate is possible correlated with the error term in equation (1), an instrumental estimation method has been used. As described in the second section, the relationship between unemployment and vacancies is determined by both the Beveridge curve and the activity curve; therefore it is preferable to estimate the Beveridge curves in the system for each labour segment. As such, the full-information methods, such as three-stage least squares (3SLS) or full-information maximum likelihood, are more preferable and efficient. These methods take account of the covariances between residuals. However, the estimation procedures are not able to converge due to explosive residuals. Therefore, this section reports the estimation results by two-stage least squares (2SLS), a limitedinformation method.

In the system, the Beveridge curve equations are exactly identified and the activity curve equations are over-identified, in which the 2SLS method can provide consistent estimates. 2SLS estimates can account for serial correlation by adding autocorrelation terms to the equation specification. The model can be transformed, if non-linear relationships are preferred, and estimated by using instrumental variables. Details of this procedure may be found in Fair (1984, pp. 210-214). The choice of instrumental variables, which follows Fair, comprises the lagged endogenous variables, namely the unemployment and vacancy rates, and the exogenous variables.

The unemployment and vacancy rates and other labour data (the replacement and immigration rates) are, by construction, stationary series being ratios bounded between zero and one. The augmented Dickey-Fuller unit root tests are able to reject the null hypothesis of 
a unit root in the most variables at either the 5 per cent or 10 per cent levels. While several of the data series are not able to reject the null hypothesis, this is due to shifting intercepts and structural breaks rather than a unit root process.

The deviation of the economic activity index from a trend, used as the indicator of the full capacity of the economy in the activity curve equations, is stationary. The annual growth rate of real GDP, representing changes in economic activity in the Beveridge curve equations, is also stationary. ${ }^{9}$ The stationary time series do not raise the problem of 'spurious regressions'.

Table 1 presents the estimation results of the Beveridge curve equation for the skilled and unskilled labour segments using 2SLS, while the companion results for the activity curve are presented in Table 2. Figure 3 is a graphical representation of the estimated Beveridge curves, given the average values of the shift variables in the sample period (while not taking account of the seasonal dummy).

This figure shows that the intercept term in the unskilled labour segment is almost threetimes higher than the intercept for the skilled labour segment while the skilled one is much flatter than the unskilled one. Bearing in mind the earlier caveat about the approximation of the vacancy series, skilled vacancies would have to have considerably longer durations than unskilled vacancies for this ordering to reverse. A sensitivity analysis has shown that even if the Australian duration differential were a factor of 2, it would not be large enough to reverse the intercept positions of the curves presented in Figure 3.

\footnotetext{
${ }^{9}$ See the appendix for the construction of these proxies.
} 
Table 1 Estimates of the Beveridge curves: skilled and unskilled

Dependent variable: Vacancy rate for each segment

\begin{tabular}{|c|c|c|}
\hline & Skilled & Unskilled \\
\hline Coefficient & $\begin{array}{l}\text { Estimate } \\
(t \text { statistic })\end{array}$ & $\begin{array}{l}\text { Estimate } \\
(t \text { statistic })\end{array}$ \\
\hline Constant & $\begin{array}{c}-0.0015 \\
(-0.15)\end{array}$ & $\begin{array}{l}-0.020 \\
(-2.13)\end{array}$ \\
\hline 1/Unemployment rate & $\begin{array}{c}0.0002 \\
(2.28)\end{array}$ & $\begin{array}{l}0.0007 \\
(3.40)\end{array}$ \\
\hline Replacement ratio ${ }_{t-1}$ & $\begin{array}{c}0.02 \\
(0.63)\end{array}$ & $\begin{array}{l}0.040 \\
(2.11)\end{array}$ \\
\hline Long-term unemployment rate t- $_{1}$ & $\begin{array}{c}-0.0003 \\
(-0.16)\end{array}$ & $\begin{array}{l}0.013 \\
(3.02)\end{array}$ \\
\hline Immigrants $_{t-3}$ & $\begin{array}{l}-0.921 \\
(-1.78)\end{array}$ & $\begin{array}{l}-3.091 \\
(-2.31)\end{array}$ \\
\hline Seasonal dummy & $\begin{array}{r}-0.0007 \\
(-3.19)\end{array}$ & $\begin{array}{l}-0.001 \\
(-4.33)\end{array}$ \\
\hline $\begin{array}{l}\text { Change in Economic activity }{ }_{t-1} \text { (growth } \\
\text { rate of real GDP) }\end{array}$ & $\begin{array}{r}-0.0001 \\
(-0.60)\end{array}$ & $\begin{array}{c}-0.0002 \\
(-0.84)\end{array}$ \\
\hline $\begin{array}{l}\text { Ratio of unemployment to vacancies in the } \\
\text { other segment }\end{array}$ & $\begin{array}{c}-0.0001 \\
(-0.88) \\
\end{array}$ & $\begin{array}{c}-0.0002 \\
(-1.75) \\
\end{array}$ \\
\hline Adjusted $R^{2}$ & 0.939 & 0.937 \\
\hline Durbin-Watson statistic & 2.06 & 1.524 \\
\hline$\rho[A R(1)]$ & 0.606 & 0.872 \\
\hline Number of observations & 50 & 50 \\
\hline Method & 2SLS & 2SLS \\
\hline
\end{tabular}

Note: The Beveridge curve equations are jointly estimated with the respective activity curves (in the following table). The dependent variables are the vacancy rates in each segment. $\rho$ is the coefficient of first-order autocorrelation in the residuals. These estimates assume that unskilled vacancy durations are 85 per cent as long as skilled durations.

Table 1 shows that while the coefficients on the reciprocal of the unemployment rates are, as expected, positive and significant, the skilled coefficient is about one third of the unskilled coefficient. As such, the Beveridge curve for unskilled labour is much steeper than the one for skilled labour, as shown in Figure 3. The Wald test statistic of 5.24 is significant to reject the null hypothesis that the two coefficients are the same. The steeper the Beveridge curve will be, the greater is the tendency for new job openings to be taken by people outside the market segment (that is, people not in the labour force or people in the other market segment) 
or the greater is the tendency for the job not to be filled. Given what is known about vacancy durations in the Netherlands and the UK, the latter is not likely to be the explanation for a steeper unskilled Beveridge curve.

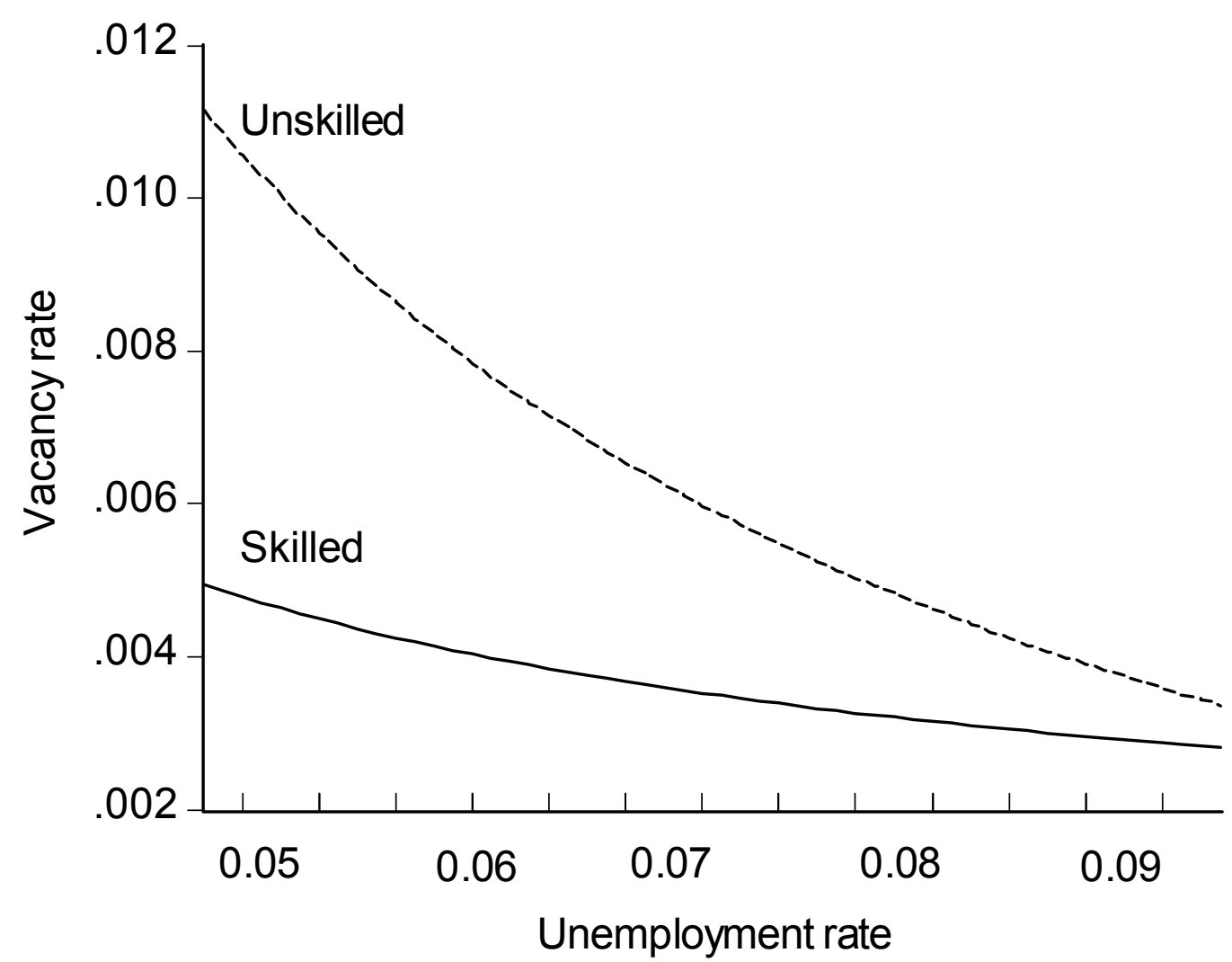

Figure 3 Beveridge curves (based on average values of the shifting variables, 1986-1999)

Except for the incidence of long-term unemployment and the replacement rate in the skilled segment, the shifting variables appear to affect the matching efficiency in the labour market. The replacement rate does not appear to affect the matching efficiency in the skilled segment but results suggest that a higher level of unemployment benefits to wages reduces either the speed of matching or the rate of job turnover in the unskilled segment. This is not surprising 
since the lower relative wages of unskilled workers makes unemployment benefits a closer alternative source of income.

The incidence of long-term unemployment does not appear to affect the matching efficiency in the skilled segment, while it is significant in the unskilled segment. A rising incidence of long-term unemployment in the unskilled segment tends to make matching slower and job turnover higher. It is possible that the de-skilling hysteresis occurs primarily in the unskilled segment.

The coefficients on immigrants (as a rate to the labour force in each segment) are negatively signed but the skilled coefficient is just significant at the 10 per cent level. The results suggest that higher rates of migration increase the efficiency of the matching process or reduce job turnover especially in the unskilled segments where the value of the coefficient is more than three-times bigger than the unskilled coefficient. This may occur because many employers do not recognise overseas qualifications and foreign skilled work experience. ${ }^{10}$ Several studies on the immigrant labour markets have attested to employers desire for local work experience and knowledge. On the other hand, a higher rate of unskilled immigration tends to hasten the matching process and decrease turnover in the unskilled segment. This most likely reflects the more urgent pecuniary needs of new immigrants who arrive with little financial reserves and assets, limited family and no access to unemployment benefits.

The seasonal dummy, corresponding to normal time of entry for education sector leavers, is significant and negative in every equation. This dummy has been included to cater for a peculiarity of the data because school/university/TAFE leavers who find a job are included in the employment data but are not included in the unemployment data unless they worked 
while studying. Accordingly in the December quarter, the denominator in the unemployment rate looks artificially higher than it would have had these people been classified for both employment and unemployment. ${ }^{11}$ The coefficients on economic growth in the both Beveridge curves are not significant.

It is possible for the labour (whether employed or unemployed) in one segment to take the vacant positions in the other segment. Since it takes time to acquire skills, the direction of flows is more likely from the skilled segment to the unskilled segment. The ratio of unemployment to vacancies in each labour segment is used as an indicator of tightness of each segment.

Table 1 shows that the tightness in the unskilled segment does not affect the matching process in the skilled segment while the tightness in the skilled segment does, as expected, have a significant impact in the unskilled job matching production. The coefficient of the skilled unemployment-vacancy ratio is negative in the unskilled Beveridge curve equation, which implies that a tighter skilled segment would hasten the matching process in the unskilled segment, but not vice versa. Put another way, the rate of downgrading of skilled job seekers is sensitive to labour market conditions but not the rate of upgrading of unskilled job seekers. This may have occurred because there is more mobility of skilled workers between segments than unskilled workers.

The estimates of the activity curve equations are reported in Table 2 . As expected, the higher the economy is above the full capacity, the higher the activity curves are and the more vacancies there are in both segment. The coefficients of first-order autocorrelation in the

\footnotetext{
${ }^{10}$ For some discussion of these issues, see Wooden (1990).

${ }^{11}$ Dummies for other quarters were not significant as expected.
} 
activity curve equations are very close to one (the null hypothesis of being equal to one cannot be rejected), which would suggest the non-stationary residuals and a cautious interpretation of the results. $^{12}$

The explanatory power of these equations in Table 1 and 2 is good. The residuals of all the equations, some after accounting for first-order autocorrelation, are normally distributed and not serially correlated.

Table 2 Estimates of the activity curves: aggregate, skilled and unskilled labour Dependent variable: $v_{i}-u_{i}$

\begin{tabular}{lcc}
\hline Coefficient & $\begin{array}{c}\text { Skilled } \\
\text { Estimate } \\
(t \text { statistic })\end{array}$ & $\begin{array}{c}\text { Unskilled } \\
\text { Estimate } \\
(t \text { statistic })\end{array}$ \\
\hline Constant & -0.023 & -0.039 \\
Seasonal dummy & $(-2.34)$ & $(-1.78)$ \\
Closeness to full capacity trend & 0.003 & 0.004 \\
line & $(7.25)$ & $(7.55)$ \\
Adjusted $R^{2}$ & 0.0014 & 0.0018 \\
Durbin-Watson statistic & $(4.86)$ & $(4.76)$ \\
$\rho$ [AR(1)] & 0.953 & 0.947 \\
Number of observations & 1.779 & 1.997 \\
Method & 0.96 & 0.97 \\
\hline
\end{tabular}

Note: The activity curve equations are jointly estimated with the two Beveridge curves (in the previous table). The dependent variable of each curve is the difference between the vacancy rate and the unemployment rate in each labour segment. $\rho$ is the coefficient of first-order autocorrelation in the residuals.

A sensitivity analysis, which assumed that skilled vacancy durations are twice durations for the unskilled, was also conducted to check the robustness of the estimation results. It is found that the sensitivity analysis yields similar results as those in Table 1 and 2 . However, with a

\footnotetext{
${ }^{12}$ The change in private investment is also put into the activity curve equations on the assumption that capital has favourable effects towards skilled labour. The test results, however, show that the coefficients on private investment are not significant. Table 2 does not report the results with private investment.
} 
higher number of vacancies for skilled labour, the intercept term of the Beveridge curve for the skilled segment is smaller than the one in Figure 2. With higher skilled vacancy durations, the Beveridge curve for the skilled segment is also flatter.

Figure 2 shows that the two Beveridge curves has shifted outward in around 1994, therefore indicates that the estimation results should be interpreted as average coefficients for the whole period and are not valid for sub-sample periods. Chow tests are applied to test possible structural change.

For the Beveridge curve in the skilled segment, it is found that if the breakpoint is assumed at the first quarter of 1994 (1994Q1), then the Chow test statistic is 7.456, which is able to reject the null hypothesis that the coefficients are the same in the two sub periods. For the unskilled segment, the Chow test statistic for the breakpoint at 1994Q1 is 8.585, which is high enough to reject the null hypothesis that the coefficients are the same in the two periods. The Chow tests show that the Beveridge curves estimated in Table 1 are general descriptions of the segmented labour market in the sample period and may not apply to the sub-sample periods. This may imply that the job matching processes in the skilled and unskilled segments were undergoing structural change in the late 1990s. Figure 2 shows that while in general there is a negative relationship between unemployment and vacancies in the unskilled segment after 1993, changes in the late 1990s were dramatic and yields an unstable relationship between them.

\section{Conclusion}

This paper finds support for the hypothesis that separate Beveridge curves exist. If it is assumed that vacancy durations are about 18 per cent longer for skilled than for unskilled, 
then the skilled Beveridge curve is flatter and lies closer to the origin than the unskilled Beveridge curve. Additional data on vacancy durations by occupation may change the relative slope and height of the curves but is less likely to change their relative distance from the origin.

Even with this caveat in mind, it appears that the skilled labour segment is more efficient at matching worker with jobs and/or has lower turnover rates. Lower turnover rates may of course be indicative of a better prior match. The higher rate of job engagements in the unskilled sector suggest that the main differences between the two Beveridge curves is driven by higher job turnover not longer vacancy durations. This is consistent with [Le, 1999 \#519] who found that high job turnover was associated with jobs of low 'quality'.

Interestingly, it was found that other shift variables, such as the replacement rate, the incidence of long-term unemployment and the immigration rate, had differential effects on each curve. There is good evidence that a higher ratio of unemployment benefits to wages weakens matching efficiency and increases job turnover only in the unskilled segment. While a higher rate of immigration tends to improve labour market matching, the effect is much more evident for unskilled labour. The incidence of long-term unemployment appears to slow the matching process in the unskilled segment, but have no effect in the skilled segment. Furthermore, the rate of movement of skilled workers between market segments appear greater than the rate of unskilled workers.

\section{Appendix - data}

Skill refers to a person's dexterity, knowledge and ability to undertake specific tasks. Common summary measures of skill include post school qualification and occupational work 
experience. It was only practical for the purposes of this paper to classify skill status by current or recent past occupation.

Australian Standard Classification of Occupations, Second Edition 1996 (ASCO, ABS Cat. no. 1220.0) has been used as the template for skill classification. Major groups 1, 2, 3 and 4 (managers and administrators, professional, associate professional and tradespersons) have been included in the skilled group. Major groups 5, 6, 7, 8 and 9 (advanced clerical and sales workers, intermediate clerical, sales and service workers, intermediate production and transport workers, elementary clerical, sales and service workers and labourers and related workers) are included in the unskilled group.

Prior to 1996 and earlier the occupational classification structure (ASCO - First Edition) was used by the Australian Bureau of Statistics and a concordance based on 1996 Census data has been produced by the ABS to assist users of occupation data to convert the ASCO First Edition data to a Second Edition basis.

Employment, unemployment and long-term unemployment (durations over 52 weeks) occupational data have been extracted from the ABS Labour Force Survey (cat. 6291.0.40.001 and cat. 6203.0).

Disaggregating vacancies has proven difficult, as there is no consistent collection of vacancies, existing or advertised, by occupation. The paper has used the ABS Job Vacancies (ABS cat. 6354.0) data as the correct measure of existing vacancies in the aggregate economy. On the basis that each new job match is associated with a prior vacancy, whether advertised or not, estimates of the relative proportions of total new job matches by skill group has been made from the ABS Labour Mobility survey (cat. 6209.0). While this ratio should reflect relative job and worker turnover, occupational structural change and the relative 
growth in employment in each segment, it assumes that each segment has the same rate of hard-to-fill vacancies. These proportions have been applied to the aggregate vacancy series from cat. 6354.0 to give thousand of vacancies in each quarter. In addition, annual Dutch data on vacancy durations (vacatures) from 1992 to 2000 has been used to weight the vacancies data. The Dutch data was divided into skilled occupations (6/7 Hogere beroepen, 8/9 Wetenschappelijke beroepen) and unskilled occupations (1 Elementaire beroepen, 2/3 Lagere beroepen). Vacancy durations are grouped into under 1 month, 1 to 3 months and over 3 months. Average durations for each skill level in each year takes the mid-point for the first two durations and assumes that the last is 4.5 months. The UK also has irregular surveys of vacancy durations. ${ }^{13}$ The 1988 survey found that while average durations for managers and professionals was 2.2 months, the rates for occupations which fit most closely with the unskilled group defined for this paper was between 1.5 and 0.6 months. ${ }^{14}$

Immigration data was provided by the Department of Immigration and Multicultural Affair (DIMA). However, DIMA only used ASCO - First Edition to classify immigrants since July 1990. Previously, occupations were defined as professional/technical, managerial/clerical, skilled, semi-skilled, and unskilled. To be consistent with the definition used in this paper, it was assumed that skilled immigrants included professional/technical and skilled. The unskilled group included DIMA's categories of semi-skilled and unskilled. For the period of July 1990 to June 2000, the number of skilled immigrants is the sum of Professional, Para-professional and Trade Persons. Unskilled included the remainder.

\footnotetext{
${ }^{13}$ For evidence on the duration of occupational vacancies in Britain, see Layard et al. (1991, p. 330).

${ }^{14}$ The unskilled Beveridge curve still lies above the skilled Beveridge curve. Similar, to the Australian gross job creation, the implied rate of UK gross job creation was higher for unskilled occupations.
} 
The replacement rate is the ratio of weekly unemployment benefits to average weekly total earnings by all employees from ABS Employee Earning and Hours, Australia (cat. 6306.0). The series of unemployment benefits is obtained from the ABS modellers' database - NIF Taxes and transfers (ABS cat. 1364.0.15.003). Earnings are concorded to ASCO First Edition using unpublished estimates from the Australian Productivity Commission and our own estimates.

The annual growth rate of real GDP is used as the indicator of the changes in economic activity, used in the Beveridge curve. The Westpac-Melbourne Institute coincident indicator of economic activity, reported monthly in Westpac-Melbourne Institute Indexes of Economic Activity, is used in activity curve. The deviation of the index from a trend, complied by the Melbourne Institute, is taken as an indicator of the economy relative to its full capacity.

Monthly data are converted to quarterly by taking the average of three monthly values and annual data is converted to quarterly by linear extrapolation. All the data series start from the third quarter of 1986 and end in the fourth quarter of 1999.

\section{References}

Baker, S., Hogan, S. and C., R. (1996), 'Is there Compelling Evidence against Increasing Returns to Matching in the Labour Market', Canadian Journal of Economics, 24, 97693.

Blanchard, O. and Diamond, P. (1989), 'The Beveridge Curve', Brookings Papers on Economic Activity, 1, 1-76.

Bleakley, H. and Fuhrer, J. (1997), 'Shifts in the Beveridge Curve, Job Matching, and Labour Market Dynamics', New England Economic Review, Sept/Oct, 3-19. 
Budd, A., Levine, P. and Smith, P. (1988), 'Unemployment, vacancies and the long-term unemployed', Economic Journal, 98, 1071-91.

Fair, R. C. (1984) Specification, Estimation, and Analysis of Macroeconometric Models, , , Harvard University Press, Boston, USA.

Jackman, R., Pissarides, C. and Savouri, S. (1990), 'Labour market policies and unemployment in the OECD', Economic Policy, , 450-92.

Layard, R., Nickell, S. and Jackman, R. (1991) Unemployment. Macroeconomic performance and the labour market, , Oxford University Press, Oxford.

Nickell, S. and Bell, B. (1995), 'The collapse in demand for the unskilled and unemployment across the OECD', Oxford Review of Economic Policy, 11, 40-62.

Pissarides, C. (1986), 'Unemployment and Vacancies in Britain', Economic Policy, 3, 499559.

Vickery, J. (1999), 'Unemployment and Skills in Australia', Research Discussion Paper, 1999-12, , Reserve Bank of Australia .

Webster, E. M. (1999), 'Labour market programs and the Australian Beveridge curve: 1978 to 1997', Economic Record, 75, 405-416.

Withers, G. and Pope, D. (1985), 'Immigration and unemployment', Economic Record, 61, 554-63.

Wooden, M. (1990), 'The labour market experience of immigrants', In Australian Immigration. A survey of the issues AGPS, Canberra, pp. 6-10. 